\title{
Evidence for a spinal stepping generator in man
}

\author{
B Bussel ${ }^{1}$, A Roby-Brami ${ }^{2}$, O Rémy Néris ${ }^{1}$ and A Yakovleff ${ }^{1}$ \\ INSERM, Institut Fédératif de Recherche sur le Handicap, ${ }^{1}$ Service de Rééducation Neurologique, Hôpital R. \\ Poincaré, Garches 92380, France; and ${ }^{2}$ INSERM CJF 93.3, 9 Quai St Bernard, Paris 75005, France.
}

Keywords: central pattern generator; paraplegic patients; spinal circuitry; spinal cord lesions

The existence of the central pattern generator (CPG) for locomotion in lower mammals has been clearly demonstrated by Brown ${ }^{1}$ who showed that rhythmic stepping like activity observed in the acute spinal cat was not due to a succession of reflexes since it persisted after peripheral deafferentation of the distal stump of the spinal cord. The physiology of the CPG has been reappraised by Lundberg's group ${ }^{2,3}$ and then extensively described in lower mammals. ${ }^{4,5}$ Spinal locomotor activity was mainly observed in acute spinal preparations after injection of cathecolaminergic drugs. ${ }^{2,4}$ Spinal locomotor activity was also observed in the chronic spinal cat but only if the cat was spinalized as a kitten ${ }^{6}$ or if the spinal section was immediately followed by daily training on a treadmill. ${ }^{7}$ In the chronic trained adult spinal cat, clonidine (which is a cathecolaminergic drug) is not necessary to induce rhythmic activity but it improves its amplitude and its regularity. ${ }^{8}$ Similarly, spinal locomotor activity can be obtained in chronic spinal rats after transplanting embryonic cathecolaminergic cells below the level of the spinal transection. ${ }^{9,10}$ In the chronic spinal monkey, the existence of this CPG was first denied. ${ }^{11}$

This assertion has been rediscussed by the same group and has led to less clear cut interpretations of the results. $^{12}$

The presence of a CPG in man is still debated and the recent paper by Illis $^{13}$ asserts that it has not been unequivocally demonstrated, following complete transection in man. Usually, patients with a clinically complete spinal cord section clearly do not recover rhythmic alternating locomotor activity as expected, although encouraging results have been obtained recently by Dietz et $a l^{14}$ and Wernig et $a l^{15}$ and described in the review by Barbeau and Rossignol. ${ }^{16}$ In addition, our group brought out two significant arguments favouring the presence of a CPG in patients with clinically complete paraplegia. First, we demonstrated that flexor reflexes in paraplegic patients are always related to the CPG network. ${ }^{17-19}$ Secondly we observed rhythmic spinal activity in a patient with a clinically complete spinal cord section (spinal myoclonus). ${ }^{20}$

Correspondence: B Bussel
Flexion reflexes and $C P G$

The electrical stimulation of the Flexor Reflex Afferents (FRA) in patients with a complete spinal cord section induces two EMG responses in the ipsilateral flexor muscles. ${ }^{17}$ The early response (latency of about $100 \mathrm{~ms}$ ) is not different from the classical flexion reflex observed in normal humans as well as in animal experiments. The second response is characterized by a lower threshold, a generalized distribution in ipsilateral flexors and a longer latency $(150-500 \mathrm{~ms})$ which increases with either increasing intensities or increasing durations of the stimulation. We demonstrated that the long latency of the second response was due to a long central delay and thus that the late flexion reflex was similar to the late flexion reflex described in the acute spinal cat with DOPA. The work from Lundberg's group and recently by Gossard et al ${ }^{21}$ have shown that the internuncial network released by Dihydroxyphenylalanine (DOPA) is related to the CPG. We demonstrated in man two important characteristics of the DOPA network observed in animal experiments: FRA stimulation may (i) induce a presynaptic inhibition of Ia terminals ${ }^{17}$ and (ii) induce a premotoneuronal inhibition of contralateral late reflexes in the flexor muscles. ${ }^{18}$ These features indicate that the organisation of neural spinal networks in paraplegic patients is similar to the DOPA network observed in animal experiments and then to the CPG.

\section{Spinal myoclonus}

Since the work of Lhermitte ${ }^{22}$ and Kuhn, ${ }^{23}$ it has been known that the human spinal cord, deprived from supraspinal influences, can generate rhythmic involuntary movements. We have had the opportunity to examine a patient with a complete spinal cord section who exhibited rhythmical contractions $(0.5 \mathrm{~Hz}$ frequency) of the trunk and the lower limb extensor muscles. ${ }^{20}$ It is not possible in man to perform large peripheral deafferentation ${ }^{1}$ or to study fictive locomotion. Fictive locomotion is studied in animals by recording electroneurograms during curarisation of the motor end plates; so the neural activity does not induce any movement and in the same way any reflex activity due to mobilisation of peripheral afferents. ${ }^{24}$ Nevertheless several arguments indicate that the rhythm is unlikely to be due to a peripheral loop but 
is probably due to intrinsic spinal activity. Three arguments favour that this myoclonus could be due to activation of the spinal stepping generator. First this rhythmic activity could be induced, stopped or modulated by FRA stimulation, secondly in some circumstances an alternating flexion-extension activity was observed, and lastly animal experiments have shown that the spinal stepping generator can induce rhythmic bursts of extensor motoneurones as observed in our patient.

\section{Conclusion}

As claimed by Illis $^{13}$, these studies do not absolutely prove the existence of a central pattern generator in man. Nevertheless there is some evidence that the spinal cord even deprived of supra spinal influence can generate rhythmic activity, and that some elements of the spinal circuitry on which the generation of stepping rhythms relies in lower vertebrates exist in man. The presence of a spinal CPG in paraplegic patients raises the hope that it could be activated by adequate training, pharmacological activation using cathecolaminergic drugs or maybe in the future by neural transplants.

\section{References}

1 Brown TG. The intrinsic factors in the act of progression in the mammal. Proceedings of the Royal Society of London 1911; B, 84: $308-319$.

2 Jankowska E, Jukes MGM, Lund S and Lundberg A. The effect of DOPA on the spinal cord. V Reciprocal organisation of pathways transmitting excitatory actions to alpha motoneurones of flexor and extensors. Acta Physiol Scand 1967; 70: 369-388

3 Lundberg A. Half centers revisited. In: Szentagothai J, Palkovits M, Hamori J (eds) Regulatory functions of the CNS. Principles of motion and organization. Academiai Kiado, Budapest; Pergamon, Oxford (1981) pp $155-167$

4 Grillner S. Locomotion in the spinal cat. In Stein RB, Pearson KG Smith RS, Redford JB. (eds). Control of posture and locomotion. (Advance in behavioral biology vol 7) Plenum New York 1973; pp 515-535

5 Grillner S, Wallen P. Central patterns generators for locomotion with special reference to vertebrates. Annu Rev Neurosci 1985; 8 $233-261$

6 Stelzner DJ, Ershler WB. and Weber ED. Effects of spinal transection in neonatal and weanling rats: survival of function. Exp. Neurol., 1975; 46: 156-177.
7 Barbeau H, Rossignol S. Recovery of locomotion after chronic spinalization in the adult cat. Brain Research 1987; 412: 184-186

8 Barbeau $\mathrm{H}$, Rossignol $\mathrm{S}$. Initiation and modulation of the locomotor pattern in the chronic spinal cat by noradrenergic, serotoninergic and dopaminergic drugs. Brain Research 1991; 546: $250-260$.

9 Yakovleff A, Roby-Brami A, Guézard B, Mansour H, Bussel B, Privat A. Locomotion in rats transplanted with noradrenergic neurons Brain Res Bull 1989; 22: 115-121.

10 Yakovleff A, Cabelguen JM, Orsal D, Gimenez M, Rajaoftra N, Drian MJ, Bussel B, Privat A. Fictive motor activities in chronic spinal rats transplanted with foetal monoaminergic neurons $\operatorname{Exp}$. Brain Res 1995; 106: 69-78.

11 Eidelberg E, Walden JG, Nguen LH. Locomotor control in macaque monkeys. Brain 1983; 104: $705-725$.

12 Vilenski JA, Moore AM, Eidelberg E, Walden J G. (1992) Recovery of locomotion in monkeys with spinal cord lesions $J$ of Motor Behavior 1992; 24: 288-296.

13 Illis LS. Is there a central pattern generator in man? Paraplegia 1995; 33: $239-240$.

14 Dietz V, Colombo G, Jensen L. Locomotor activity in spinal man. Lancet 1994; 344: $1260-1263$.

15 Wernig JF, Muller S. Laufband locomotion with body weight support improved walking in persons with severe spinal cord injuries. Paraplegia 1992; 30: 229-238.

16 Barbeau H, Rossignol S. Enhancement of locomotor recovery following spinal cord injury. Current opinion in neurology 1994; 7: $517-524$.

17 Roby-Brami A, Bussel B. Long latency spinal reflex in man after flexor reflex afferent stimulation Brain 1987; 110: $707-725$.

18 Roby-Brami A, Bussel B. Effects of flexor reflex afferent stimulation on the soleus $H$ reflex in patients with a complete spinal cord lesion: evidence for a presynaptic inhibition of Ia transmission. Exp Brain Res 1990; 81: 593-601.

19 Roby-Brami A, Bussel B. Inhibitory effects on flexor reflexes in patients with a complete spinal cord section Exp. Brain Res 1992; 90: $201-208$

20 Bussel B, Roby-Brami A, Azouvi P, Biraben A, Yakovleff A, Held JP. Myoclonus in a patient with a spinal cord transection. Possible involvement of the spinal stepping generator Brain. 1988; 111: $1235-1245$

21 Gossard JP, Brownstone RM, Barajon I and Hultorn $\mathrm{H}$ Transmission in a locomotor-related group Ib pathway from hindlimb extensor muscles in the cat. Exp Brain Res 1994; 98: $213-228$

22 Lhermite J. La section totale de la moelle dorsal.. Tardy Pigelet Bourges 1919.

23 Kuhn RA. Functional capacity of the isolated human spinal cord. Brain 1950; 73: 1 - 51 .

24 Perret C. Neural control of locomotion in the decorticate cat. In Neural control of locomotion. Herman RM, Grillner S, Stein PSG and Stuart DG Eds Plenum Press New York, 1976, pp 587-615. 